\title{
TOMAR PARTE, DISTRIBUIR PODER OU DESISTIR? A PARTICIPAÇÃO JUVENIL NA VIIDA CULTURAL, SOCIAL E POLÍTICA
}

\section{TAKING PART, SHARING POWER, OR HEADING FOR THE EXIT? YOUTH PARTICIPATION IN CULTURAL, SOCIAL AND POLITICAL LIFE}

\author{
Birgit ERIKSSON $^{2}$ \\ Tradução de Simone do Vale - PPGMC/UFF
}

\begin{abstract}
Resumo: A participação apresenta formas novas e interessantes de co-criação, engajamento cívico e emancipação, mas, também, demandas e legitimações altamente problemáticas. Este trabalho aborda o caráter ambivalente da participação cultural e cívica por meio de uma simples pergunta: que sensação ela provoca? Em primeiro lugar, examino como a agenda participativa é experimentada na vida cotidiana de um grupo de estudantes dinamarqueses. Em segundo lugar, a maneira como eles reagem à participação e, em terceiro, os motivos pelos quais eles reagem das maneiras como o fazem. $\mathrm{O}$ artigo se baseia em textos e entrevistas produzidas por 34 alunos de graduação e 36 mestrandos de vários programas de pós-graduação em Estética da Universidade de Aarhus, Dinamarca.
\end{abstract}

Palavras-chave: Participação; Cidadania; Juventude; Cotidiano.

\begin{abstract}
:
Participation presents both interesting new forms of co-creation, civic engagement and empowerment, and highly problematic demands and legitimizations. In this work, I will approach this double-edged character of cultural and civic participation by asking the simple question "how does it feel?". I will examine, first, how the participatory agenda is experienced in the everyday lives of a group of young Danish students, second, how they react to it, and third, why they react in the ways they do. Empirically, the article is based on texts and interviews produced by 34 undergraduates and 36 master's students on various aesthetic study programmes at Aarhus University, Denmark.
\end{abstract}

Keywords: Participation; Citizenship; Youth; Everyday Life.

\footnotetext{
1 Originalmente publicado em Nielsen, H. K., Fiig, C., Loftager, J., Olesen, T., Stephensen, J. L. \& Sørensen, M. P. (org.). The Democratic Public Sphere: Current Chalenges and Prospects. Aarhus: Aarhus Universitetsforlag, 2016, pp. 149-174.

2 Professora do Programa de Pós-Graduação em Estética e Cultura, School of Communication and Culture, Aarhus University, Dinamarca.Email: aekbe@dac.au.dk.
} 


\section{Introdução}

Dentro e fora das instituições, a agenda participativa está em ascensão. Enquanto as instituições políticas tradicionais enfrentam uma crise, e o sistema democrático parece estar perdendo legitimidade, especialmente entre os jovens, os novos repertórios participativos evoluem. Visíveis nas artes, na mídia e nos movimentos sociais do início do século XXI, esses repertórios costumam se mostrar diversificados e efêmeros demais, afetivos e fragmentários demais para se enquadrar na ideia clássica de uma esfera pública genérica e fundamentada principalmente pela razão. Contudo, os novos repertórios participativos (ou, ao menos, aqueles abordados aqui) evoluem em um espaço público compreendido como um espaço inclusivo e deliberativo (DRYZEK, 2009): no espaço abstrato da mídia (social) e das comunidades online, nos espaços definidos institucionalmente para as exposições artísticas, as performances e os movimentos sociais, e nos espaços físicos como as salas de aula e as praças urbanas, os cidadãos participam de uma variedade de processos culturais, sociais e políticos no espaço público. A ideia - e o ideal - de cidadão e de envolvimento do usuário parece estar em toda parte: na co-criação e engajamento cívico no mundo da arte, na mídia, nas instituições de assistência social e tomada de decisão política. Obviamente, alguma coisa diferente está acontecendo, já que nos deparamos cada vez mais com novos e variados fenômenos participativos na nossa vida cotidiana.

$\mathrm{Na}$ academia, também, o interesse pela participação está em ascensão. A participação já era um tema de interesse dos estudos de desenvolvimento, da teoria democrática e dos estudos sobre comunicação comunitária e alternativa dos anos 1960 e 70. Porém, no novo século, ela se tornou algo cada vez mais importante para a pesquisa em estética, novas mídia, juventude e sociologia, para citar apenas alguns.

Talvez, esse interesse acadêmico crescente possa ser explicado em virtude de a cultura participativa estar ganhando força e presença, enquanto nós estamos nos tornando mais conscientes de viver numa cultura participativa. Outra razão, porém, talvez seja o fato de que a participação cidadã é cada vez mais importante, embora problemática, ao mesmo tempo, como solução para desafios sociais urgentes. A 
participação não é apenas reivindicada pelos cidadãos. Ela também é algo que se exige dos cidadãos para que as instituições e a sociedade funcionem. Para reformular a frase de Hegel, talvez tenha sido porque o crepúsculo caiu para as formas tradicionais de cultura participativa - o voto fiel nas eleições, a afiliação nos sindicatos, o voluntariado em associações, o acompanhamento das instituições culturais - que a coruja de Minerva abriu as suas asas. Em suma, a questão é que, ou se trata do declínio da participação na vida social, política e cultural, ou, ao contrário, de uma genuína revitalização da democracia que motivou o estudo intensificado da co-criação e do engajamento cidadão.

Em contrapartida, a questão citada acima é uma motivação importante para este artigo. A sua premissa é que o presente interesse na participação é ambivalente. Como pesquisadores e habitantes da cultura contemporânea, nós encontramos muitos experimentos participativos novos e promissores. No entanto, em muitos desses experimentos, a participação assume a forma não de uma prática horizontalizada, emancipatória e cotidiana, mas antes de um ideal utópico, uma demanda estrita ou uma legitimação duvidosa para cortes de verba e decisões políticas obscuras (ARNSTEIN, 1969; WHITE, 2011; JANCOVICH; BIANCHINI, 2013). Em alguns casos, a participação aparece ora como um efeito inevitável ou como solução problemática para questões relativas às agendas econômica e política em sociedades pós-Estado de BemEstar. Mas, em outros, o envolvimento de cidadãos e usuários aparenta ter o potencial para reinventar a democracia (cultural). Não é só porque o crepúsculo está começando a cair sobre a cultura participativa que o interesse por ela cresce e Minerva levanta voo. A participação apresenta formas novas e interessantes de co-criação, engajamento cívico e emancipação, mas, também, demandas e legitimações altamente problemáticas. Em seguida, eu abordo esse caráter ambivalente da participação cultural e cívica por meio de uma simples pergunta: que sensação ela provoca? Em primeiro lugar, examino como a agenda participativa é experimentada na vida cotidiana de um grupo de estudantes dinamarqueses. Em segundo lugar, a maneira como eles reagem à participação e, em terceiro, os motivos pelos quais eles reagem das maneiras como o fazem.

Empiricamente, o artigo se baseia em textos e entrevistas produzidas por 34 alunos de graduação e 36 mestrandos de vários programas de pós-graduação em estética na Universidade de Aarhus, Dinamarca. Quase todos os estudantes de graduação têm 
pouco mais de vinte anos de idade, enquanto os mestrandos estão na faixa dos 25 , com alguns em cada grupo um pouco mais novos ou mais velhos. Esse grupo de alunos oferece perspectivas interessantes sobre a participação cultural porque todos experimentam as práticas midiáticas participativas e a agenda participativa das políticas culturais desde a adolescência, e porque, em geral, todos são usuários/produtores frequentes, intensos e criativos (BRUNS, 2008) de arte e cultura.

O primeiro grupo de textos foi escrito entre fevereiro e abril de 2014, quando 34 alunos do segundo ano de cinco cursos de graduação em estética redigiram um breve ensaio sobre as suas experiências e expectativas pessoais referentes à ideia de participação. Os estudantes, que cursaram uma disciplina eletiva sobre novas formas de participação cultural, foram solicitados no início do curso a escrever sobre formas de participação que considerassem importantes para si mesmos, quer fosse cultural, social ou política. Como consequência da pergunta aberta, as respostas foram muito pessoais e diversificadas, confirmando que mesmo em um grupo relativamente homogêneo de estudantes universitários, jovens indivíduos praticam a participação de maneiras diferentes e têm ideias muito divergentes quanto à importância de várias formas de participação cultural, social e política.

O segundo grupo de textos consiste dos resultados de uma pesquisa conduzida pelos graduandos no final do mesmo semestre com outros 34 jovens - o único requisito foi que os entrevistados não deveriam ser estudantes, também (por exemplo, jovens profissionais, alunos de outras faculdades, imigrantes, desempregados ou habitantes das áreas rurais). Em grupos, os alunos escreveram guias de entrevista (novamente, sobre as experiências e expectativas em relação à participação), conduziram as entrevistas e produziram um relatório sobre os resultados. Finalmente, em sala de aula, comparamos as compreensões de participação que foram articuladas no guia de entrevista, as entrevistas e os relatórios e tiramos algumas conclusões.

O terceiro grupo de textos foi produzido em setembro de 2015 por 36 alunos no primeiro ano do mestrado no programa de pós-graduação em Estética e Cultura. No início do semestre, os grupos de alunos escreveram sobre conectividades e coletividades na arte e na cultura. As perguntas que eles foram solicitados a responder diziam respeito a sua própria participação cotidiana, com um foco específico em: a) o (novo?) apelo da 
participação conectiva/coletiva na arte e na cultura, bem como os seus dilemas e potenciais inerentes; e b) os tipos diferentes de arte e de apelo à participação na arte que, talvez, realcem novos entendimentos de individualidade, coletividade $\mathrm{e}$ conectividade no mundo da arte e fora dele.

A partir do uso dos três grupos de textos produzidos pelos estudantes de graduação e mestrado, eu apresento como, enquanto usuários intensivos de arte e cultura, eles concebem a participação e se relacionam (ou não) com as questões de identidade, comunalidade, mídia social e política. Para investigar não só "qual é a sensação de participar", mas também para compreender por que se pode sentir de uma determinada maneira, discutirei os resultados empíricos no seguinte enquadramento teórico e contextual.

Em primeiro lugar, faço uma distinção entre dois entendimentos de participação, como relacionados a identidades compartilhadas (um discurso sociológico) ou à tomada de decisão democrática (um discurso político). Eu argumento que os jovens, em geral, compreendem a participação (deles) segundo um viés sociológico, não politicamente, e que eles ainda associam participação a um discurso de mercado. Assim, examino como isso está intimamente ligado às possibilidades participativas que lhes são oferecidas por instituições culturais e estratégias de extensão comunitária.

Em segundo lugar, cito exemplos e discuto os aspectos mais problemáticos da agenda participativa (e, portanto, o contexto discursivo dos alunos) por meio da descrição sobre o modo como as autoridades procuram cidadãos participativos tanto no nível da União Europeia quanto no nível local em Aarhus. Baseado em casos concretos, o discurso dos estudantes é aqui situado em um pós-Estado de Bem-Estar e um contexto pós-político (MOUFFE, 2005).

Em terceiro lugar, analiso como a individualização em um "mundo líquido moderno" (BAUMAN, 2011) afeta a participação e a maneira como os jovens a concebem. Desse modo, estabeleço como um evento específico - a crise de refugiados europeia e dinamarquesa no outono de 2015 - afetou a concepção dos estudantes quanto às ideias de participação, comunicação e coletividade. Eu demonstro como essa crise foi articulada pelos estudantes e interpreto essas articulações por meio do uso dos conceitos de "públicos organizados" (KELTY; 2013) e de nova "ação conectiva" (BENNETT; 
SEGERBERG; 2013). Concluo com a indicação de alguns potenciais da participação e, ao menos, do que não deveríamos fazer se quisermos compreender alguns deles como opostos à degeneração da ideia de participação em demandas pós-políticas para os cidadãos.

\section{Tomar parte ou distribuir poder}

Pode-se distinguir entre (ao menos) dois discursos sobre a participação. No primeiro, a participação é entendida como "partilha" e está intimamente associada a identidades compartilhadas ou pertencimento a uma comunidade. Esse discurso está presente na sociologia, mas também no campo cultural onde as instituições ou conselhos administrativos contabilizam os participantes em um determinado evento ou atividade - geralmente, com o objetivo de aumentar o número de participantes.

No segundo discurso, a participação se refere à distribuição de poder. Na influente definição de Carol Pateman, "participação" é um direito e significa ter "poder igualitário para determinar o resultado de decisões" (1970, p.71). Em teoria política, uma "participação significativa é definida como distribuição de poder" (CAMMAERTS et al., 2013, p. 647). Nesse discurso, costuma-se encontrar hierarquias de participação: parcial versus participação total (PATEMAN, 1970), manipulação vs. Controle cidadão (ARNSTEIN; 1969) ou, mais geralmente, falsa participação versus verdadeira - a primeira indicando que as pessoas são levadas a crer que influenciam o processo de tomada de decisão quando, na realidade, influenciam pouco ou nada. Nico Carpentier se baseia nessa compreensão política para distinguir entre acesso, interação e participação, definindo essa última como "um processo político - no sentido amplo do conceito de política - onde os atores envolvidos nos processos de tomada de decisão se posicionam uns em relação aos outros por meio de relações de poder que são (até certo ponto) igualitárias" (CARPENTIER, 2011, p. 354). Nessa perspectiva política, a participação é uma pré-condição para a co-determinação e a democracia.

$\mathrm{Na}$ cultura participativa contemporânea, o discurso sociológico aparenta prevalecer. Esse, pelo menos, é o caso da Dinamarca, e de maneira muito significativa, dos textos produzidos pelos estudantes daqui. Nas suas redações sobre participação, o 
discurso de identidade foi excepcionalmente predominante: a maioria descreveu a participação como a integração em uma comunidade. Entre os textos individuais sobre participação dos 34 universitários (o primeiro grupo de textos citados na introdução), poder e democracia só foram mencionados uma vez e, provavelmente não por coincidência, pelo único aluno que não possuía cidadania dinamarquesa. Como cidadã alemã, ela não tinha o direito de votar para o parlamento dinamarquês e, portanto, faltava-lhe o mais tangível e básico dos direitos democráticos.

Provavelmente, a razão pela qual os outros alunos não comentaram sobre o voto não foi o fato de que eles o julgassem irrelevante, mas antes porque consideram o voto como algo garantido. Apesar do comparecimento às urnas ter declinado entre os jovens, a vasta maioria deles ainda vota. Quando indagados se votaram em uma eleição política nos últimos três anos (EUROPEAN COMMISSION, 2015), 68\% dos jovens dinamarqueses responderam positivamente. Além disso, Cammaerts et al. argumentam, de maneira convincente, que não se deve usar os baixos índices de comparecimento às urnas entre os jovens eleitores como indicação de desprezo pelo voto. Baseado em uma pesquisa de opinião de massa em seis países europeus, eles descobriram que:

na sua esmagadora maioria, os jovens que votam associam esse ritual a um vasto conjunto de emoções positivas. Em particular, o voto faz com que se sintam interessados, parte das suas comunidades, que de fato fazem parte de um momento importante para o país, que carregam a responsabilidade nos ombros, animados e até felizes (CAMMAERTS et al., 2014, p.652).

É notável, porém, que a maioria dos universitários dinamarqueses no meu estudo - e também aqueles que eles mesmos entrevistaram - não tenha associado participação a questões de poder, co-determinação ou democracia. Eles simplesmente não compreendem o conceito em termos políticos.

Claro, pode ser que os estudantes - matriculados em vários programas de arte e humanidades - estivessem mais interessados na participação cultural do que na participação social e política (e esperassem que a professora também estivesse, embora as questões apresentadas a todos explicitamente abordassem bem mais do que participação cultural). Porém, mesmo quando se enfoca a participação cultural, isso não implica que as questões de poder e co-determinação sejam irrelevantes. Como Claire Bishop e outros definiram, a arte participativa tem sido instrumentalizada nas políticas 
culturais do Reino Unido e da União Europeia, onde ela se tornou uma espécie de engenharia social soft, intimamente ligada ao desmonte do Estado de Bem-Estar Social. No Reino Unido, a participação se transformou em um chavão importante do discurso da inclusão social, mas ao contrário da sua função na arte contemporânea (onde ele denota autopercepção e ação coletiva), para o New Labour, "participação" se referia efetivamente à eliminação de indivíduos disruptivos. Ser incluído e participar na sociedade significa se conformar ao pleno emprego, ter renda disponível e ser autossuficiente" (BISHOP, 2012, p.13-4).

A arte participativa e a participação em geral podem, então, desempenhar um papel altamente ambivalente. Quando as agendas participativas da arte e da cultura funcionam como meios de inovação, integração e coesão social, a participação tende a perder o seu papel subversivo ou antiautoritário e a se alimentar da lógica social, econômica e altamente politizada das políticas sociais e econômicas pós-industriais. Com muita frequência, "a participação na sociedade corresponde meramente a participar da tarefa de ser individualmente responsável pelo que, no passado, era uma preocupação coletiva do estado" (Ibid. p.14).

$\mathrm{Na}$ Dinamarca, a agenda participativa foi adotada em 2008 por meio da política nacional de cultura com o programa Reach Out (Estenda a Mão), e uma fase complementar com recomendações mais específicas em 2012 (Reach Out 2008; 2012). As palavras-chave para os programas sociais do Ministério da Cultura são "envolvimento do usuário" e "inovação produzida pelo usuário", e os dois principais objetivos são atrair novos públicos e inovar as instituições culturais para melhorar o impacto social. Os universitários do nosso estudo comentam esses dois programas sociais em particular. No entanto, os alunos de mestrado refletem claramente sobre a ampla implementação dos programas por meio da afirmação de que "um maior envolvimento do usuário é uma forte tendência” (grupo 9) na cultura contemporânea, enquanto consideram "óbvia a transformação da relação entre emissor e receptor, que assume cada vez mais a forma de um diálogo" (grupo 7).

Os estudantes refletem sobre a tendência participativa, mas nenhum deles a compreendem por um viés político na linha de Carpentier ou Bishop. Quando solicitados a refletir sobre a participação na vida cultural e social, eles não demonstram 
interesse nos problemas que as pessoas enfrentam para influenciar os processos de tomada de decisão. Eles percebem essa questão por um ângulo inverso, escrevendo principalmente sobre os desafios que as instituições culturais e sociais enfrentam para envolver as pessoas. O que os estudantes consideram mais interessante e problemático é, em síntese, não a maneira como eles ou outros conquistam o direito de participar, mas antes o oposto: como vários organizadores e instituições fazem as pessoas participarem na cultura e na sociedade.

\section{Participação em oferta}

Quando os estudantes escrevem sobre os esforços para fazer as pessoas participarem em uma determinada atividade, eles os fazem por meio de um quadro discursivo no qual as palavras-chave não são igualdade, democracia, emancipação, comunidade ou coisa semelhante. Ao contrário, eles empregam o vocabulário de um discurso de marketing - oferta, atenção, competição, liberdade de escolha e daí em diante. Eles descrevem as maneiras como vivem em uma sociedade na qual muitas ofertas culturais não são apenas dirigidas a segmentos específicos, mas também ajustadas a hábitos e gostos pessoais. Muitos deles comparam as suas vidas culturais offline à experiência de receber, constantemente, ofertas online que se baseiam em buscas, compras e "curtidas" prévias, assim parecendo "feitas sob medida para eles". Os estudantes descrevem como eles podem escolher e dispor de uma abundância de músicas, filmes, eventos, etc., sendo raramente confrontados ou envolvidos em coisas que não capturam a sua atenção imediata.

Neste ambiente carregado de apelos estéticos e ofertas feitas sob medida para o indivíduo, as instituições de arte e cultura precisam disputar a atenção e a participação dos estudantes. Os alunos perceberam duas estratégias específicas: a arte é embalada em eventos sociais e situada no exterior, no espaço público. A primeira estratégia se torna visível quando as instituições de arte tentam oferecer tanto ao público novo quanto antigo uma sensação de pertencimento e identidade comum por meio da oferta de vários programas de fidelidade e eventos sociais. Um grupo de mestrandos vê "um desdobramento interessante [nas instituições de arte]: a arte raramente está sozinha, 
mas, em geral, acompanhada por algum tipo de evento social focado na coletividade" (grupo 5).

Um exemplo mencionado por diversos estudantes é o museu de arte ARoS em Aarhus. Semelhante às iniciativas em muitas outras instituições, o museu elaborou um programa para o público jovem chamado ARoS 27, assim como o 27 Lounge, um clube que convida os jovens membros a passar a noite no museu com palestras, música, bebidas e socialização. Alinhadas à compreensão dos próprios estudantes, as iniciativas participativas do museu se baseiam claramente na perspectiva sociológica e não política do conceito. Em suma: para atrair um público jovem, ARoS não concede nenhuma influência sobre as atividades e prioridades do museu, mas oferece descontos, toca música e serve drinques. Os universitários parecem bastante ambivalentes em relação a esse desdobramento. Eles são convidados para recepções, vernissages, inaugurações e coisas do tipo, a ponto de fazer um dos grupos perguntar retoricamente: "existe algum problema em se deixar a arte falar por si de vez em quando?” (grupo 7).

Quase todos os alunos notaram a segunda estratégia - que um número cada vez maior de obras-de-arte ou projetos são exibidos fora do museu, em zonas urbanas, comerciais ou espaço público. Essa estratégia de "extensão" se volta principalmente para aqueles que podem não ser considerados pessoas que frequentam museus ou teatros por conta própria. Em geral, essas iniciativas tentam fazer com que os cidadãos participem nos processos/trabalhos artísticos e que a arte participe da vida social. Um exemplo disso é fornecido por Christian Lollike, um diretor de arte dinamarquês que, no festival anual de Aarhus, em setembro de 2015, criou dois projetos no espaço público urbano. Em We are not real (LOLLIKE, 2015a), desenvolvido com Jens Folmer Jepsen, diretor do Festival de Aarhus, Lollike instalou esculturas realistas de refugiados afogados nas ruas de Aarhus. Ao caminhar pelas ruas, era possível se deparar de repente com quatro corpos de refugiados arrastados pelo rio que corta o centro da cidade. Lollike não se envolveu apenas com o trágico destino dos refugiados no Mediterrâneo, mas também com os cidadãos a caminho do trabalho, compras ou de uma cafeteria - cidadãos que, provavelmente, não haviam planejado fazer parte do público de uma exposição de arte, mas que foram convidados a se envolver mais profundamente 
com a obra por meio da leitura de algumas frases de refugiados náufragos reais dispostas junto às esculturas em uma cesta com biscoitos da sorte.

Um modo mais direto e provocador de engajar os cidadãos de Aarhus e os visitantes do festival foi colocado em ação com The Provocateur de Lollike. Essa performance, que a exemplo de We are not real, viajou para várias cidades europeias, consiste de um homem sentado em uma jaula numa praça pública que grita com os transeuntes, confronta-os com declarações e perguntas provocadoras, pedindo para que eles despertem:

Prezados todos. Sou novo no país. Vocês podem me ajudar com alguns esclarecimentos? Como anda a política de dois pesos, duas medidas? E a liberdade de expressão? E a tolerância? E o racismo? E a xenofobia? E a indiferença? E a alienação? E o terrorismo de estado? $\mathrm{E}$ a democracia? [...] E a economia? E os princípios? E a coesão? E a força de vontade? Em outras palavras, o quanto o seu capitalismo é flexível? (SORT; HVID 2015a)

Em Aarhus, ela assumiu uma forma especial:

Eu estava na 'cidade dos sorrisos' - Aarhus - terra da liberdade de expressão. Eu me disfarcei de turco. De alguém em busca de asilo. De aproveitador. De ansiedade. 'Atire em um turco', gritei, 'venha visitar o seu medo - nesse país você pode dizer qualquer coisa'. Eles acabaram de tentar incendiar um centro de refugiados - a poucos quilômetros de Aarhus. Perguntei se eles conhecem a voz interior, aquela que quer mandar os refugiados de volta para casa (Id 2015b).

$\mathrm{Na}$ performance, a conflituosa recepção dinamarquesa aos refugiados foi confrontada de forma direta. E a audiência foi autorizada a reagir; em Aarhus, como num jogo típico dos parques de diversão, podia-se até atirar bolas para derrubar o artista, o que um dos membros da plateia conseguiu.

Em We are not real e The Provocateur, Lollike se engaja explicitamente em um conflito político e social premente - a crise dos refugiados - e tenta provocar empatia, raiva, medo, culpa e reflexão. As suas instalações e performances são impressionantes, e dificilmente é possível sair sem ser afetado por elas. Mas a sua obra também é um entre os muitos exemplos de uma estratégia de extensão cada vez mais comum, por meio da qual somos solicitados a interagir e participar da arte no espaço público de maneira muito explícita e "ruidosa". De maneira reveladora, como um dos grupos de mestrandos 
sintetizou a sua experiência no processo: "antigamente, precisávamos buscar a arte, mas chegamos a um ponto onde é a arte que procura por nós” (grupo 7).

\section{Aprendendo a participar (do jeito certo)}

O que acontece, então, se mudarmos o foco da vida cultural para o domínio da política? Também atingimos um ponto onde, como cidadãos, já não buscamos o poder, mas o poder procura por nós? Em vários níveis, parece ser esse o caso - especialmente para os jovens. Na União Europeia, por exemplo, a "participação na vida democrática" não é só um direito fundamental, mas algo cada vez mais desejado, em particular entre os jovens cidadãos. No Tratado de Lisboa (2007), o Artigo 165 enfatiza a importância de se "encorajar a participação dos jovens na vida democrática na Europa" (CAMMAERTS et al.; 2014;p.646). Desde então, a crise econômica agravou o medo de ver os jovens se tornarem cidadãos pessimistas, apáticos, desiludidos ou radicais, e inúmeros documentos e iniciativas da Comissão Europeia (European Commision) descreveram a participação total da juventude na sociedade como um desafio societário fundamental que precisa ser solucionado, por exemplo, recorrendo-se às seguintes estratégias: "aumento da participação da juventude na vida cívica das comunidades locais e na democracia representativa, apoio às organizações de jovens, bem como das várias formas de se 'aprender a participar', estímulo da participação de jovens não organizados" (EUROPEAN COMMISSION, 2009, p.8). Sobretudo, um dos principais objetivos da estratégia para a juventude da UE 2010-2018 é "encorajar os jovens a participar ativamente na sociedade" (Id, 2016).

Até o momento, a Comissão Europeia ainda não conseguiu encorajar a juventude a participar. A razão para isso, provavelmente, é a suposição generalizada de que jovens desagregados são aqueles que precisam "aprender a participar" na democracia existente. Contrariando essa interpretação, porém, Cammaerts et al. estudaram a atitude de jovens europeus em relação à vida democrática e concluíram que, em geral, o motivo para que eles não participem é uma profunda insatisfação:

A nossa pesquisa destacou a incongruência entre as expectativas dos jovens em relação à democracia e a maneira como elas são tratadas (ou não) pelos políticos. Qualquer um que pense que o baixo índice de comparecimento às urnas dos jovens eleitores se deve ao fato de que 
as pessoas são preguiçosas ou egoístas demais para se dirigir até a zona eleitoral está deturpando grosseiramente o imenso apetite político da juventude europeia. Contudo, ao mesmo tempo, a mensagem contundente que os jovens nos deram foi "Queremos votar e votar nos deixa entusiasmados, mas vocês precisam nos levar a sério e nos tratar como pessoas inteligentes". Os nossos dados confirmam que a maioria dos jovens são mais críticos do que apáticos; isto é, eles estão insatisfeitos com a oferta política e não cansados da política. (2014, p.661).

Em outras palavras, o problema pode ser a suposição de que os jovens não têm competências participativas, enquanto aqueles no poder sabem como praticar a política e podem continuar fazendo o que sempre fizeram.

Não é só no contexto da União Europeia que se pode afirmar que o poder está buscando os cidadãos; isso também acontece em nível nacional e local. Um exemplo recente pode ser encontrado em uma nova política de cidadania lançada pela prefeitura de Aarhus em setembro de 2015. De acordo com o website do prefeito, esse plano de ação foi desenvolvido em cooperação com não menos de 700 cidadãos de Aarhus e, no final, ele foi submetido a um processo de consulta pública - tudo de forma aparentemente muito participativa e democrática.

No corpo do projeto e na sua introdução, porém, democracia e co-determinação são apenas citadas muito brevemente. Ao invés disso, o texto enfoca a sensação de pertencimento e a identidade compartilhada: "Enquanto cidadãos de Aarhus, somos parte de algo muito maior do que nós mesmos"; como diz o título, nós estamos "juntos por Aarhus" (SAMMEN OM AARHUS 2015a, tradução da autora). Enfatizando a necessidade de envolver a todos na solução dos desafios societais e usando inúmeras palavras com conotações suaves e positivas, o "conselho da cidadania" (Medborgerskabsudvalget) explica que:

Aarhus enfrentará numerosos desafios nos próximos anos. O estado de bem-estar social está sendo desafiado pelas mudanças demográficas e as pesadas restrições financeiras. Manter e desenvolver uma sociedade de bem-estar sustentável social e economicamente requer que políticos, cidadãos, empresas, associações e funcionários do município (aqui referidos como "nós" ou cidadãos de Aarhus) repensem a maneira como nos unimos por Aarhus. A cidadania em Aarhus significa aquilo que podemos fazer juntos. As oportunidades são infinitas. As palavras-chave são co-criação, co-propriedade, coesão e comunidade (Ibid., tradução da autora). 
Surpreendentemente, co-determinação e democracia não se encontram entre as palavras-chave, enquanto as responsabilidades e deveres ofuscam muito os direitos: "a ambição é que todos que vivem, trabalham ou estudam em Aarhus assumam as rédeas da própria cidadania" (Ibid.). E nós, os cidadãos, "devemos ser sensatos em nossas demandas à comunidade e ao município" (SAMMEN OM AARHUS 2015b, p. 2). Não apenas somos cada vez mais requisitados a sermos autossuficientes, como Bishop argumenta, mas também se espera que aceitemos a responsabilidade pela comunidade sem esperar muito em troca.

A política de cidadania de Aarhus ressalta dois problemas gerais da cultura participativa. O primeiro diz respeito à sociedade pós-estado de Bem-Estar. Mesmo em estados de Bem-Estar Social consolidados como a Dinamarca, agora muito parece depender da participação e das intervenções de cidadãos ativos. A participação cidadã é cada vez mais apresentada como a única solução para os problemas que surgem quando poderosas forças econômicas transnacionais desafiam as autoridades e instituições públicas, que não conseguem mais sustentar ou garantir a sociedade de Bem-Estar. O estado está encolhendo sob a globalização neoliberal, e todos os cidadãos são convocados para assumir uma responsabilidade pessoal por tarefas que costumavam ser responsabilidade do estado (ou da municipalidade).

$\mathrm{O}$ segundo problema se refere à sociedade pós-política. O plano de ação do Conselho da Cidadania retrata uma sociedade na qual não existem conflitos e nenhuma alternativa política: "nós estamos unidos por Aarhus". As diferenças culturais e as várias perspectivas são apenas brevemente mencionadas no texto, e de modo a sugerir que elas podem e devem constituir um conjunto harmonioso. O que é apresentado, portanto, é um quadro hegemônico de uma comunidade sem lugar para a oposição e sem necessidade para a luta. Basicamente, o texto sabe o que é bom para todos. E isso esconde as escolhas políticas que o antecipam, por exemplo, o fato de que os desafios deverão ser solucionados não pelas instituições e agências de assistência social, mas individualmente, por cidadãos mais ou menos dispostos. Apresenta-se a política de cidadania como se não houvesse alternativa. Mas sempre existem alternativas e escolher entre elas é exatamente a essência da política: "questões políticas em si sempre envolvem decisões que requerem fazer uma escolha entre alternativas conflitantes" 
(Mouffe; 2008, p.8). Em vez de articular essas alternativas conflitantes - e enfrentar, por exemplo, as ambivalências, desigualdades, contradições e interesses opostos que se fazem presentes por meio de obras-de-arte como as de Lollike - a política de cidadania institui uma visão pós-política de que todos somos iguais, unânimes e unidos por Aarhus. Consequentemente, define-se uma política de conduta na qual o político é desempenhado no plano do "registro da moralidade" (cf. MOUFFE, 2005, p. 72-6) um registro segundo o qual não se é a favor ou contra uma determinada ordem social, mas um bom ou mau cidadão, uma pessoa responsável ou egoísta.

\section{Participação individualizada e espontânea}

Agora, retornando à condição pós-estado de Bem-Estar, a questão é se devemos tentar - por meio da apresentação aos cidadãos da participação como a solução dos problemas numa sociedade de Bem-Estar reduzida - rejuvenescer um mundo que envelheceu: um mundo que agora conseguimos enxergar porque o crepúsculo caiu sobre ele. Pois como essa terceirização da sociedade de Bem-Estar para os cidadãos se reconcilia com a individualização da modernidade tardia analisada por inúmeros sociólogos? De certa maneira, claro, ela se encaixa muito bem quando a participação se transforma na individualização dos problemas políticos e sociais - quando precisamos encontrar soluções individuais para problemas sistêmicos, para reformular o argumento de Ulrich Beck. Ele e Elizabeth Beck-Gernsheim, de modo otimista, insistiram nos potenciais sociais da atual "ética da plenitude e realização individual" (2002, p.22-23). Num tom mais pessimista, Zygmunt Bauman argumentou que vivemos em uma "era de desagregação" (2001, p.39), na qual os bem-sucedidos são individualizados na sua rejeição ao compromisso de longo prazo com comunidades éticas, aceitando-as apenas caso elas não restrinjam o direito de viver uma vida independente. Os bem-sucedidos simplesmente têm muito pouco a ganhar e muito a perder em uma rede restrita de obrigações comunitárias como aquelas definidas pelas comunidades tradicionais.

Caso Bauman tenha razão, a participação cidadã enfrenta um problema óbvio. Quanto o estado encolhe, a fidelidade ao estado declina nas mesmas proporções. E, enquanto as autoridades e instituições públicas precisam cada vez mais de participação, 
elas também enfrentam cada vez mais problemas para incentivá-la. Consequentemente, elas criam planos de ação.

Nas instituições culturais, encontramos um problema e reação paralelos: quando a crença em uma cultura unificada desaparece, a fidelidade às instituições culturais declina. Assim, as instituições inventam toda sorte de iniciativas sociais, programas de fidelidade e extensão para impedir que o público frequente outros lugares. Bauman analisou esse desdobramento em A Cultura no Mundo Líquido Moderno (2011). Ele distingue a nossa compreensão de cultura entre três estágios. No primeiro estágio, a cultura era um agente de mudança, cujo objetivo era "educar as massas e refinar seus costumes, e assim melhorar a sociedade e aproximar 'o povo', ou seja, os que estão na 'base da sociedade', daqueles que estão no topo" (2011, p. 7). Pensava-se que a cultura deveria ser de todos e que as suas funções eram civilizar e democratizar. Esse conceito foi virado do avesso por Pierre Bordieu, que estudou a cultura não como um agente de mudança, mas como um pacificador. Essa foi a segunda fase: a cultura a serviço da "monótona repetição da sociedade e da manutenção de um sistema de equilíbrio" (Ibid., p.11). No entanto, a análise de Bourdieu também é um instantâneo da cultura pouco ante a inevitável perda da sua posição, causada pela transição da modernidade "sólida" para o seu estado "líquido". Nessa terceira fase, a cultura - liberada das obrigações societais das duas etapas anteriores - pode "concentrar-se na realização das necessidades individuais, resolvendo os problemas individuais e o enfrentamento dos desafios e atribulações da vida pessoal" (Ibid., p.12). A cultura, e em especial a esfera artística, "é moldada para se enquadrar na liberdade individual de escolha e na responsabilidade individual por essa mesma escolha; e [...] a sua função é assegurar que a escolha seja e continue a ser uma necessidade e um dever inevitável da vida" (Ibid.).

Com a análise de Bauman em mente, faz sentido que um dos grupos de mestrandos tenha escrito sobre como eles e outros jovens gostam tanto de festivais porque a motivação não é a ocasião social, mas o fato de que os festivais possibilitam e requerem que eles selecionem e tomem uma decisão. Também faz sentido que uma das conclusões gerais dos estudantes de graduação (no workshop de apresentações orais) fosse que os jovens querem oportunidades casuais e descompromissadas de 
participação. Não há terreno para a espontaneidade. Com frequência, os jovens só sabem se podem ou querem participar em cima da hora.

A preferência por essas e outras formas "líquidas" de participação é um óbvio desafio para instituições e agências públicas mais tradicionais ou consolidadas. E, o que é pior, em geral se torna uma desculpa para não se levar os jovens a sério, mesmo quando eles apenas estão fazendo o que deveriam: tomar parte em redes soltas e inconstantes, tentando, da melhor maneira possível, ser bem-sucedidos no mundo da modernidade tardia, onde flexibilidade, mobilidade e a capacidade de escolher para agir sem regras determinadas ou objetivos fixos são altamente apreciadas ou até mesmo necessárias para o sucesso (cf. BOLTANSKI; CHIAPELLO; 2005). Contudo, em muitas instituições culturais, as oportunidades para envolvê-los são desperdiçadas. Convida-se os jovens para eventos sociais ou para 'brincar', mas eles não têm voz, nem influência com a consequência lógica de que eles, geralmente, perdem o interesse e procuram outros lugares (cf. ERIKSSON; STEPHENSEN, 2015). Como os universitários também concluíram na oficina: “Os jovens precisam ser levados a sério. Eles não devem ser subestimados (como em pseudo-diálogos e participação de mentirinha)". Para eles, formas casuais e espontâneas de participação não são sinônimo de desagregação. Ao contrário, uma terceira conclusão da oficina foi que a participação precisa fazer uma diferença tangível: "A participação precisa conduzir a algum lugar e é importante que nós [...] possamos ver um efeito ou resultado da nossa participação, seja fazer alguma coisa pelos outros ou conseguir algo para si”. Ver que a participação cria um valor para si mesmo, para os outros ou para a sociedade é motivador. Precisa haver uma espécie de "cenoura pendurada à frente" para se encorajar os jovens a participar. Pode ser uma oportunidade para fazer novos contatos, mudar coisas, aprimorar o currículo ou se divertir.

Assim como os jovens não veem nenhuma contradição entre a sua necessidade de serem levados a sério e a sua preferência pela participação espontânea, eles também não reconhecem nenhum conflito em querer criar um valor "para si mesmos, para os outros ou para a sociedade" ou em querer mudar as coisas ou se divertir. Mas que tipo de engajamento e ações podem corresponder a essas demandas? 
Novos moldes de ação?

A dupla demanda dos estudantes - fazer a diferença, mas espontaneamente; divertir-se, mas ser levado a sério - impõe um desafio não só para as instituições e agências políticas tradicionais, mas para o nosso tradicional entendimento de participação e da relação entre as ações individuais e coletivas. Um dos esforços mais produtivos para enfatizar essa compreensão tem sido o conceito de "ação conectiva" descrito por Lance Bennett e Alexandra Segerberg. A premissa dos autores em The Logic of Connective Action (2013) é que a diminuição a longo prazo do número de filiações nas organizações civis e políticas, somada à personalização dos estilos de vida e das práticas midiáticas, transformou a maneira como as pessoas se envolvem na política.

Nos protestos prolongados em larga escala da última década - tipicamente relacionados à justiça econômica ou à mudança climática - Bennett e Segerberg se depararam com uma participação política cada vez mais personalizada (com públicos muito individualizados). Para interpretar esse desdobramento, os autores desenvolveram o conceito de "ação conectiva", que é uma forma de contestação baseada no compartilhamento de conteúdo personalizado nas mídias sociais. Eles fazem uma comparação com a ação coletiva, uma forma mais familiar com lideranças fortes, organizações convencionais e a formação de identidades coletivas. Bennett e Segerberg argumentam que as ações coletivas organizadas de modo mais convencional se tornaram paralelas e, em alguns casos, substituídas pela nova lógica das ações conectivas, desempenhadas por pessoas que não querem "unir-se a organizações políticas formais ou adotar definições dos seus problemas que exijam uma troca das crenças pessoais por uma identificação grupal mais restritiva” (2013, p.1). Nas redes de ação conectiva, caracterizadas por um "ethos de diversidade e inclusão" (Ibid., p.4), as pessoas compartilham conteúdo por meio das mídias sociais, como, por exemplo, as variantes do meme "Eu sou os 99\%".

Nas organizações de ação coletiva, o problema mais comum tem sido "convencer indivíduos a contribuir para um esforço coletivo" cuja finalidade é alguma espécie de bem comum, quando "individualmente, é racional não contribuir, apesar de todos 
concordarem que tudo seria melhor caso todos o fizessem" (Ibid., p.31). Nas redes de ação conectiva, porém, o desafio não é convencer os indivíduos a contribuir. Eles já o fazem diariamente quando oferecem o trabalho livre de "compartilhar" nas mídias sociais. Antes, o desafio aqui é como transformar essas práticas midiáticas em “engajamento público, foco em políticas ou impacto na mídia de massa” (Ibid., p.58). Uma das maneiras como isso vem sendo feito nos movimentos de protesto ao redor do mundo é por meio da performance física do "ethos de diversidade e inclusão" nas praças públicas, somando, portanto, a presença física ao compartilhamento digital. As interações entre as práticas online e presenciais são complexas e cada vez mais importantes - como demonstrado de forma criativa e eficiente pelos manifestantes virtuais que, sob a forma de holograma, tomaram as ruas da Espanha para protestar contra uma lei antiterrorismo que tornou ilegal protestar (fisicamente) diante de prédios oficiais (PLATT; VARGAS, 2015). Apesar dessa criatividade, porém, a lei permaneceu em vigor, assim como o desafio de criar (nos termos de DRYZEK, 2009, p. 1386) transmissões do público para o espaço emancipado.

O fato de que a presença física é importante, não só para o resultado da ação contenciosa, mas também para a participação em geral, foi um ponto final com que os estudantes de graduação concordaram no workshop: "Não basta engajar os jovens nas redes sociais. As redes sociais não são suficientemente engajadoras e devem ser combinadas com formas de participação do tipo 'mão na massa', nas quais eles estão fisicamente presentes". Sobretudo, um aspecto surpreendente dos textos dos universitários foi que ele não entendem o seu próprio uso (muito intenso) das redes sociais como relacionado à cidadania ou participação em sociedade. Contrariando a ideia de ação conectiva de Bennett e Segerberg, em geral, eles não concebem as suas próprias práticas nas redes sociais como "participação real". Quando um grupo perguntou a não-universitários se eles "experimentaram um aumento da participação na sociedade por causa das plataformas de mídias digitais" (grupo 1), nenhum dos entrevistados compreendeu a pergunta. Outro grupo, inclusive, até considerou "impopular e inaceitável” ser muito ativo nas redes sociais - compartilhar, comentar e "fazer muito barulho". 
No entanto, é interessante que o conceito de rede social dos mestrandos seja muito diferente. Um grupo identificou o Facebook como "a mídia que pode ser considerada a nossa fonte principal de notícias referentes à sociedade, cultura e as artes", acrescentando que "muita gente usa o Facebook como um acesso imediato à informação sobre o mundo que nos cerca - quando alguma coisa importante acontece, nós claramente esperamos que ela não escape à atenção do Facebook, isto é, da nossa rede" (grupo 3). Em comparação aos alunos de graduação, em geral, eles foram muito mais positivos em relação ao potencial informativo, cívico e político do seu "feed diário" nas redes sociais.

Eu defendo que a razão para essa diferença não é que os dois grupos de estudantes usem as mídias sociais de modos distintos, mas, antes, que eles produziram as suas redações em contextos muito diversos ${ }^{3}$. Os universitários, que só consideraram as plataformas digitais como um lugar para a informação política e cidadã e o debate em um grau muito restrito, produziram os seus textos sobre participação na primavera de 2014, um período relativamente calmo na (pós) política dinamarquesa.

Os estudantes de mestrado, ao contrário, escreveram sobre as suas práticas participativas e conectivas em setembro de 2015, quando a crise dos refugiados atingiu a Dinamarca. Eles vivenciaram como os refugiados não cruzaram apenas a fronteira nacional, mas também a fronteira dos seus feeds de notícias, afetando-os profundamente:

[Antes] quando as fotos eram distribuídas nos jornais, elas não influenciavam necessariamente a vida privada, mas, hoje, nós temos a sensação de que não se pode escapar delas quando se está online [...]. Em relação à crise dos refugiados, nós experimentamos uma forma $\mathrm{e}$ um nível de atividade sem precedentes no Facebook. De fato, podemos dizer que o Facebook interage com o mundo da vida e que ele é mais do que a representação do self digital? (grupo 3)

\footnotetext{
${ }^{3}$ Um motivo para a atitude dos graduandos pode ser, também, é claro, a sua adesão a uma concepção habermasiana clássica da esfera pública, e o fato de não perceberem as suas conversas e compartilhamentos cotidianos mais informais em vários sub-públicos e semi-públicos como contribuições democráticas válidas. Eles têm um conceito bastante tradicional e exclusivo do que é político - talvez, também, porque estivessem escrevendo no âmbito de uma universidade, tentaram ser "plus royaliste que le roi" ao excluir todas as conversações informais que podem ser consideradas como particulares ou conversa fiada. Essas conversações informais cotidianas online - ou offline - acarretam implicações deliberativas e políticas mais importantes do que foi, contudo, defendido pelo próprio Jürgen Habermas (1996) e, de modo mais radical, por acadêmicos como Lisbet van Zoonen (2005), Todd Graham (2011) e Scott Wright (2012).
} 
Assim como os mestrandos imaginaram que notícias importantes do (seu) mundo não escapariam à atenção do Facebook (ou das suas redes pessoais), eles mesmos não conseguiram escapar da conectividade do Facebook. No seu feed pessoal, a foto do corpo de Aylan Kurdi, um menino de três anos de idade, em uma praia da Turquia se revezou com atualizações dos amigos que compartilhavam imagens de festas de aniversário dos seus filhos incomensuravelmente mais afortunados. A mistura originou uma forma de texto muito especial - e uma leitura que explicita a dificuldade de se ignorar o contraste entre a alegria nas atualizações dos amigos pessoais e as atualizações que mostravam a desigualdade e a crueldade do mundo.

Embora não pudessem escapar da rede e da conectividade, porém, os mestrandos não perceberam o potencial ativista e político da sua própria participação online. Fundamentalmente, eles descrevem a si mesmos como leitores com a possibilidade de compartilhamento:

As fotos de refugiados e as reações a elas estimulam a participação individual, conectiva e coletiva: a participação individual porque recebemos no feed diário, onde temos a oportunidade de curtir, compartilhar e comentar. Algumas apelam a um senso de conectividade, de humanidade universal, um reconhecimento de que estamos conectados a um mundo global. Outros apelos enfatizam o coletivo, que deveríamos proteger nossas fronteiras para garantir que a comunidade e a economia dinamarquesas não sofram sob a influência estrangeira (grupo 4).

Esta é uma noção altamente política da participação mediada porque ela remete às seguintes perguntas: Quem somos nós? O que constitui o que entendemos como "nós"? Estamos realmente juntos (em Aarhus)? E como vários tipos de "nós" se relacionam uns com os outros? Questões como essas são indagadas frequentemente no Facebook sempre que somos convidados não só para curtir e compartilhar postagens, mas também para participar e convidar outras pessoas para vários eventos, além de criar, seguir e ser membro de diversos grupos. A partir da crise dos refugiados, eles se tornaram ativos de um modo que é comparável ao efeito das obras de Lollike descritas anteriormente porém, talvez com um potencial participativo mais relevante.

Quando os estudantes encontram esses apelos, eles também escolhem quais deles curtir, circular e comentar. Ao fazê-lo, eles contribuem para os sentidos que são compartilhados socialmente e podem constituir um "público organizado" (KELTY 
2013, p. 25). Um público organizado tem fronteiras porosas para um público genérico virtual que, como Kelty sugere, pode existir apenas nas concretizações dos públicos organizados: uma entidade ad hoc que emerge "sempre que um grupo de indivíduos começa a prestar atenção em algo e continua desde que interajam com outros que também estão prestando atenção" (Ibid., p. 27).

Se definimos um público dessa maneira - como uma entidade ad hoc dependente da atenção e interação, ao invés de uma esfera pública generalizada com traços deliberativos específicos - penso que os estudantes serão capazes de reconhecer o potencial público e democrático daquilo que eles fazem o tempo inteiro: curtir e acompanhar, escrever e compartilhar. E com o conceito de públicos organizados, nós, como acadêmicos, também podemos compreender o pertencimento e a integração dos estudantes que, em um público organizado, é "informal, temporária e constituída principalmente por meio da atenção" (Ibid., p.25), mas que ainda pode ser muito forte, como é evidente nos públicos organizados em torno dos refugiados.

Em suma: analisar a participação dos estudantes - incluindo a sua concepção e possibilidades de participação - na vida cultural, social e política online/offline revela uma discordância entre os acontecimentos e os potenciais participativos que ainda são ignorados. Diferente da interpretação generalizada de que a juventude não se interessa e é incapaz da participação cultural, cidadã e democrática "real", eu tentei estabelecer como tanto os textos dos próprios estudantes e teorias importantes sobre engajamento democrático, ação conectiva e participação cultural apontam para outra direção. Eles revelam potenciais significativos que não são percebidos, além de formas de participação nas quais o pessoal e o político, o privado e o público, poder e identidade não são tão fáceis de separar como nas concepções clássicas de participação apresentadas no início deste capítulo. Sobretudo, eles apontam numa direção que não conseguiremos seguir enquanto pensarmos que a participação juvenil precisa se ajustar às condições pós-políticas e pós-estado de Bem-Estar predeterminadas, sob as quais se espera que eles aprendam com aqueles que detém o poder, ao passo em que todo o resto permanece no mesmo lugar de sempre. 
Referências

ARNSTEIN, Sherry R. A ladder of citizen participation. Journal of the American Institute of Planners, 35:pp. 216-24, 1969.

BAUMAN, Zygmunt. Community: Seeking safety in an insecure world. Cambridge: Polity, 2001.

Culture in a liquid modern world. Cambridge: Polity, 2011.

BECK, Ulrich \& Beck-Gernsheim, Elizabeth. Individualization: institutionalized individualism and its social and political consequences. London: Sage, 2002.

BISHOP, Claire. Artificial Hells. Participatory art and the politics of spectatorship. London: Verso, 2012.

BOLTANSKI, Luc \& CHIAPELlO, Eve. The New Spirit of Capitalism. International Journal of Politics, Culture, and Society 18:pp.161-88, 2005.

BRUNS, Axel. "The Future Is UserLed: The Path towards Widespread Produsage", Fibreculture Journal 11, 2008. Acessado em: 21 de Março, 2016. Disponível em: $<$ http://eprints.qut.edu.au $>$.

CAMMAERTS, Bart; BRUTER, Michael; BANAJI, Shakuntala; HARRISON, Sarah \& ANSTEAD, Nick. The Myth of Youth Apathy: Young Europeans' Critical Attitudes Toward Democratic Life. American Behavioral Scientist 58:pp.645-64, 2014. doi: 10.1177/0002764213515992

CARPENTIER, Nico. Media and Participation: A Site of Ideological-Democratic Struggle. Bristol, Chicago: Intellect, 2011.

DRYZEK, John S. Democratization as Deliberative Capacity Building. Comparative Political Studies 42:1379-402, 2009. doi: 10.1177/0010414009332129

ERIKSSON, Birgit \& STEPHENSEN, Jan Løhmann. Rethinking participation and re-enacting its dillemmas? Conjunctions 2:pp.48-66, 2015.

EUROPEAN COMMISSION. An EU strategy for youth-Investing and empowering: A renewed open method of coordination to address youth challenges and opportunities, 2009. Acessado em 21 de Janeiro de 2016. Disponível em: $<$ http://eurlex.europa.eu/legalcontent/EN/TXT/PDF/?uri=CELEX:52009DC0200\&from $=\mathrm{EN}>$.

Flash Eurobarometer 408 'European Youth. Brussels: European Commission, Directorate-General for Education and Culture, 2015. Acessado em 21 de Janeiro de 2016. Disponível em: <http://opendata.europa.eu/en/data/dataset/S2009_408_ENG>.

EU Youth Strategy, 2016. Acessado em 21 de Janeiro de 2016. Disponível em: <http://ec.europa.eu/youth/policy/youth_strategy/index_en.htm>. GRAHAM, Todd. What's reality television got to do with it? Talking politics in the net-based public sphere. In: BRANTS, K. \& VOLTMER, K. (org.). Political 
communication in postmodern democracy: Challenging the primacy of politics. Basingstoke: Palgrave Macmillan, 2011, pp. 248-64.

HABERMAS, Jürgen. Between facts and norms: Contributions to a discourse theory of law and democracy. Cambridge: MIT Press, 1996.

JANCOVICH, Leila \& BIANCHINI, Franco. Problematising participation. Cultural Trends 22:2., 2013. doi:10.1080/09548963.2013.783158

KELTY, Chris. From participation to power. In: DELWICHE, Aaron \& HENDERSON, Jennifer J. (org.). The Participatory Cultures Handbook. Nova Iorque: Routledge, 2013, pp.22-31.

LOLIKKE, Christian. We are not real. 2015a. Acessado em 21 de Janeiro de 2016. Disponível em: $<$ http://christianlollike.dk/projects/we-are-not-real/ $>$.

. The Provocateur. 2015b. Acessado em 21 de Janeiro de 2016.

Disponível em:

$<$ http://christianlollike.dk/projects/the-provocateur/>.

MOUFFE, Chantal. On the Political. Londres: Routledge, 2005. . Art and Democracy. Art as an Agonistic Intervention in Public Space. Art as a Public Issue. Open nr. 14. Roterdã: NAi Publishers, 2008.

Sort/Hvid. The Provocateur. 2015a. Acessado em 21 de Janeiro de 2016. Disponível em: $<\mathrm{http}: / / \mathrm{www}$.theprovocateur.dk/about/>.

The Provocateur. 2015b. Acessado em 21 de Janeiro de 2016. Disponível em: http://www.theprovocateur.dk/project/aarhus/>.

PATEMAN, Carol. Participation and democratic theory. Cambridge: Cambridge University Press, 1970.

PLATT, Gareth \& VARGAS, Marc. "Spanish hologram protesters: 'Virtual reality demo was our only option." International Business Times, 15 de Abril de 2015. Acessado em 21 de Janeiro de 2016. Disponível em: $<$ http://www.ibtimes.co.uk/spanish-hologram-protesters-virtual-reality-demo-was-ouronly-option-we-wont-repeat-it-1496552 >.

Reach Out! Inspiration til brugerinddragelse og innovation i kulturens verden. Setembro, 2008. Kulturministeriets tværgående projektgruppe. Acessado em 21 de Janeiro de 2016. Disponível em: $<\mathrm{http}$ ://kum.dk/uploads/tx_templavoila/ReachOut_Web.pdf $>$.

. Inspirationskatalog - naviger i brugerinddragelse og brugerdrevet innovation. 2012 (April). Center for Kultur og Oplevelsesøkonomi og Kulturministeriet. Acessado em 21 de Janeiro de 2016. Disponível em: $<$ http://kum.dk/uploads/tx_templavoila/reachout2012.pdf $>$.

Sammen om Aarhus. Introduktion til medborgerskabspolitikken 0,4. 2015a. Acessado em 21 de Janeiro de $2016 . \quad$ Disponível em: $<$ http://www.medborgerskabiaarhus.dk/ /media/Subsites/Medborgerskab-I- 


\section{eCOt DiAno}

Aarhus/Dokumenter/Politik-i-hoering/Introduktion-til-medborgerskabspolitikken-04.pdf $>$. Medborgerskabspolitik version 0,4. 2015b. Acessado em 21 de

Janeiro de 2016.2 Disponível em:
$<$ http://www.medborgerskabiaarhus.dk/ /media/Subsites/Medborgerskab-IAarhus/Dokumenter/Politik-i-hoering/Medborgerskabspolitik-04.pdf $>$. VAN ZOONEN, Lisbet. Entertaining the Citizen: When Politics and Popular Culture Converge. Lanham: Rowman and Littlefield, 2005.

WHITE, Sarah. Depoliticizing development: the uses and abuses of participation. In: CORNWELL, Andrea (org.). The Participation Reader, edited by Andrea Cornwell, London: Zed Books, 2011/1996, pp.57-69.

WRIGHT, Scott. From 'Third Place' to 'Third Space': Everyday Political Talk in Non-Political Online Spaces. Javnost — the public 19:5-20, 2012. 